\title{
JUSTIFICACIÓN DE LA DEMOCRACIA Y LÍMITES A LA DECISIÓN POR MAYORÍAS
}

\section{Introducción}

a justificación de la democracia es un tema recurrente en la abundante y fecunda
producción científica del profesor Elías Díaz. Desde el ya clásico y siempre
actual Estado de Derecho y Sociedad Democrática hasta el reciente los
Intelectuales contra el poder, pasando por sus importantes artículos publicados
en Cuadernos para el Diálogo en la dictadura de Franco y Sistema en el inicio de la transición, constituye una clave de lectura de su obra.

En las líneas que siguen me propongo contrastar la tesis de E. Díaz sobre la legitimidad y justicia de los regímenes democráticos con las restricciones que las tesis del coto vedado, y de la inalienabilidad de los Derechos Humanos comportan al principio de decisión por mayorías. Para ello partiré de algunos presupuestos de la democracia como la legitimidad y la autonomía que justifican el poder y la decisión individual respectivamente. Analizaré a continuación, el relativismo y la tolerancia, como caracteres que entre otros permiten distinguir los sistemas democráticos y finalmente, confrontaré el resultado, con las restricciones antes mencionadas a la decisión de las mayorías.

\section{Presupuestos de la democracia}

\section{II.1. Legitimidad}

Partiendo del concepto de legitimidad que siguiendo a J. de Lucas consiste en «la cualidad que se atribuye a un orden jurídico político y que supone su reconocimiento como dominación, y el 
reconocimiento de su capacidad para dictar órdenes que deben ser obedecidas ${ }^{1}$, la tesis de E. Díaz afirma que la decisión de las mayorías no es un requisito suficiente, aunque sí necesario, de todo régimen democrático, y que en consecuencia la legitimidad, si bien no coincide con la justicia, sí es, un elemento esencial para identificar y justificar los regímenes democráticos. Dice textualmente E. Díaz: «una teoría de la legitimidad y una teoría de la justicia son cuestiones sin duda íntimamente unidas, y a la vez claramente diferenciables, en donde la primera es la parte y la segunda el todo, por tanto habrá que convenir en que caben un Derecho y un Estado legítimos, que poseen suficiente legitimidad y que, sin embargo, no todo lo que produzcan sea ya, por ello mismo, justo; y viceversa, que pueda darse algún caso de justicia concreta en el marco de ordenamientos jurídico-políticos carentes, cabe decir, de suficiente legitimidad $»^{2}$.

Bobbio y Peces-Barba comparten la tesis de E. Díaz que identifica justicia del Derecho y legitimidad del Poder como dos elementos inescindibles. Para el Rector de la Universidad Carlos III, «situar el Poder (legítimo) como el origen del Derecho, desmiente el idealismo iusnaturalista sobre la racionalidad del fundamento de validez del Derecho positivo y confirma la conclusión confirmada por el análisis empírico de que el Derecho Positivo es válido con independencia de su justicia». Desde su concepción del normativismo realista define, siguiendo al último Kelsen, a Bobio, a Hart y al propio E. Díaz el poder como el hecho fundante básico necesario pero insuficiente de cualquier régimen jurídico que requiera la obediencia de los ciudadanos para lo cual precisa de la realización de valores (superiores) que por su incorporación al ordenamiento jurídico podrán ser exigidos coactivamente constituyéndose en un test de legitimidad del propio ordenamiento. La relación entre Derecho y Poder -dice Peces-Barba-, «supone finalmente reconocer que la justicia del Derecho es inseparable de la legitimidad del Poder, que si queremos saber cuál es el Derecho justo tendremos que plantearnos previamente cuál es el poder legítimo», concluyendo de modo categórico que «el fundamento de un Derecho justo es un poder legítimo» ${ }^{3}$. Esta tesis salva

${ }^{1}$ Cfr. De Lucas, J., Légitimité, en Dictionnaire encyclopédique de théorie et de sociologie du droit, París, LGDJ, 1988, págs. 225 y ss.

${ }^{2}$ Cfr. Díaz, E., La justificación de la democracia, Sistema, n. ${ }^{\circ}$ 66/85, págs. 3-23, ahora en Ética contra política. Los intelectuales y el poder, Madrid, CEC, 1990, págs 17-53. Vide del mismo autor Legitimidad democrática versus legitimidad positivista y legitimidad iusnaturalista, en $A D H s$, n. ${ }^{\circ}$ 1/82, págs, 51-72. Notas (concretas) sobre legitimidad y justicia en J. Muguerza y otros, El fundamento de los derechos humanos, ed. a cargo de G. Peces-Barba, Madrid, Debate, 1989, págs. 145-153.

${ }^{3}$ Cfr. Peces-Barba, Martínez, G., Introducción a la Filosofía del Derecho., Madrid, Debate, 1984 (2. ${ }^{\text {a }}$ ed.), págs. 320 y ss. Del mismo autor cfr. Los valores 
el objetivismo iusnaturalista y a la vez, los distintos formalismos que imponen sus concepciones de la justicia al margen de la legitimidad y/o consentimiento de los ciudadanos, sin incurrir en la «reductio ad hitlerum». Como advierte Bobbio, «poner como fundamento último de un orden jurídico positivo el poder no quiere decir reducir el derecho a la fuerza, sino simplemente reconocer que la fuerza es necesaria para la realización del Derecho» ${ }^{4}$.

Sin embargo, esta es una cuestión no exenta de problemas. Laporta señala como la legitimidad y la justicia de una norma no son elementos que necesariamente deban coincidir punto en el que los autores citados anteriormente estarían de acuerdo, advirtiendo además que la legitimidad no es un elemento que de por sí contribuya o aminore la justicia de una norma: «una norma jurídica justa, escribe Laporta, no pierde un ápice de su fuerza moral por haber sido dictada mediante un procedimiento no democrático; igualmente, una norma jurídica injusta no pierde un ápice de fuerza moral por haber sido emanada de un órgano perfectamente representativo» ${ }^{5}$. Totalmente de acuerdo con la posición de Laporta, pero el problema no es la justificación moral sino la jurídica. En ese caso estaríamos en presencia de un Derecho justo pero ilegítimo que actuaría como instancia crítica frente a la legalidad legítima (es el supuesto histórico del Derecho natural) o de un Derecho injusto pero legítimo (supuesto del positivismo ideológico o del legislador que pierde la legitimidad quod exercitium ante el que cabría recurrir a las ficciones o al derecho a mentir.

Podrá haber también casos en que legitimidad y justicia coincidan; es el supuesto del art. 1 de nuestra Constitución que constituye la norma básica del sistema ${ }^{6}$, y reúne lo que para Ferrajoli definen los criterios de legalidad o validez formal (quién y cómo se manda), y los de validez substancial o material (que se manda), y vincula materialmente a los poderes públicos a la garantía de los derechos

superiores, Madrid, Tecnos, 1984. Finalmente vide, Curso de Derechos Fundamentales (I) Teoría General. En colaboración con Rafael de Asís y Ángel Llamas Cascón, Madrid, Eudema, 1991, cap. 8 .

${ }^{4}$ Cfr. Bobbio, N., Teoria del Ordinamento Giuridico, Torino, Giappichelli ed., 1960, págs. 61 y ss. También de Bobbio, vide Del Derecho al Poder y viceversa, en Contribución a la Teoría del

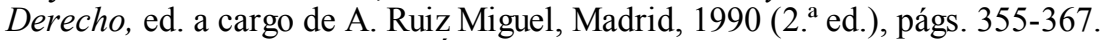

${ }^{5}$ Cfr. Laporta, F. J., Ética y Derecho, en A.A. V.V., Historia de la Ética 3. La Ética contemporánea. La Ética contemporánea. (Victoria Camps ed.), Barcelona, Crítica ed., 1989, págs. 282 y ss.

${ }^{6} \mathrm{Cfr}$. Laporta, F., Norma básica, Constitución y decisión por mayorías, en Revista de las Cortes Generales, n. ${ }^{\circ}$ 1/84, págs. 35-57. Peces-Barba Martínez, G., Los valores superiores, Madrid, Tecnos, 1984, págs. 92 y ss. Ahora en Entre el Derecho y la Moral, México, Fontanara, ed. 1993, pág. 82. 
fundamentales ${ }^{7}$. En nuestro ordenamiento jurídico, el artículo $1 .^{\circ}$ de la Constitución que es la Norma básica del sistema establece la conexión entre legitimidad del poder y justicia de las normas, realizando, por primera vez en la historia del constitucionalismo la síntesis entre contenidos formales y materiales del Derecho, e introduciendo unos valores superiores que sin perder la condición de normas directa e inmediatamente aplicables, definen la legitimidad material del ordenamiento. La consideración de norma jurídica directa e inmediatamente aplicable de la Constitución y por consiguiente de los valores y principios, permite definirlos como conceptos abiertos al cambio y no como concepciones cerradas e inmunes a la decisión por mayorías y al cambio histórico ${ }^{8}$.

En definitiva, sin legitimidad no hay justicia, aunque la legitimidad no agota la justicia. De ahí la necesidad de justificación del razonamiento jurídico, que exige que la solución adoptada no sólo sea justa sino que además esté justificada, y la presencia en nuestros sistemas jurídicos de casos fáciles (si es que aún cabe mantener la tesis del silogismo en la aplicación de las normas), de casos difíciles en los que el establecimiento de la premisa normativa y/o fáctica es problemática (prácticamente la mayoría), y finalmente de casos trágicos 9 .

\section{II.2. Autonomía}

En el ámbito filosófico-político el reconocimiento de la autonomía deriva del valor general de la libertad e igualdad y se manifiesta en el pluralismo político y la tolerancia. De ahí la conexión que no pocos autores establecen entre el principio de autonomía y la constitución de un régimen democrático de modo que el reconocimiento de uno sea condición del otro. La autonomía es condición del establecimiento del poder normativo de los individuos que implica el reconocimiento de su status como sujetos de derechos y

${ }^{7}$ Cfr. Ferrajoli, L., Dirito e Ragione. Teoria del Garantismo Penale, Bari, Laterza, 1990, cap. XIII, págs. 895 y ss.

${ }^{8}$ Cfr. García de Enterría, E., La Constitución como norma y el Tribunal Constitucional, Madrid, Civitas, 1981, págs. 226 y ss. Prieto Sanchís, S. L., Estudios sobre Derechos Fundamentales, Madrid, Debate, 1990, págs., 87 y ss., y Pérez Luño, A. E., Concepto y concepción de los Derechos Humanos, en DOXA, 4/87, págs. 47-66.

${ }^{9}$ Cfr. Atienza, M., Las razones del Derecho. Teorías de la Argumentación jurídica, Madrid, CEC, 1991. Del mismo autor, La huelga de hambre de los GRAPO. Las razones del Derecho y las decisiones jurídicas, en CLAVES, n. ${ }^{\circ}$ 14/91, págs.8-18. Prieto, L., Ideología e interpretación jurídica, Madrid, Tecnos, 1987. 
obligaciones y su condición de ciudadanos frente al Estado; autonomía y derecho subjetivo expresan el poder del individuo como titular de derechos y obligaciones y son por ello requisito necesario pero insuficiente del régimen democrático. Ahora bien, dado que ningún derecho es absoluto e ilimitado y que una característica fundamental del Estado constitucional es el igual sometimiento de ciudadanos y poderes públicos al imperio de la Ley, la autonomía no puede entenderse, como ya apuntó Kelsen, en el sentido fuerte de autodeterminación o autogobierno, sino en el más débil que comporta la capacidad de darse Leyes a sí mismo y a los demás, o lo que es igual, de autogobernarse con sujeción a lo establecido en las Leyes.

Quienes piensan que la voluntad de la mayoría no conoce límite alguno están por la primacía del principio liberal del que es expresión máxima la autonomía moral del sujeto que en su sentido más fuerte consiste en la capacidad de darse leyes a sí mismo y de no obedecer a nadie más que a sí mismo en la línea de Rousseau, Kant y Mil ${ }^{10}$. En su sentido débil, la autonomía siguiendo a Locke, es compatible con un catálogo de derechos «inalienables» que la razón debe descubrir y el derecho proteger, siendo compatible, mediante el establecimiento de un sistema constitucional de frenos y garantías, con el principio de mayoría que a través del sufragio universal especifica el régimen democrático.

En uno y otro supuesto la autonomía es condición sine qua non de legitimidad del sistema democrático; el individualismo ontológico que siguiendo a Bobbio parte del presupuesto de la autonomía de todo individuo respecto a todos los otros y de la igual dignidad de cada uno, y el individualismo ético «según el cual todo individuo es una persona moral» ${ }^{11}$, que se manifiesta mediante el ejercicio de la libertad, serán sus fundamentos. Sin libertad (externa) puede que haya autonomía como sucede históricamente con las concepciones morales de los estoicos y quizá, con el régimen paternalista en Kant, pero sin autonomía, sin poder de decisión individual no es posible el ejercicio de la libertad. Esta tesis conecta directa e inmediatamente con la fundamentación de la democracia en la tradición individualista, que no excluye la existencia de límites, ni la adopción de medidas paternalistas (justificadas) y entiende la democracia como un sucedáneo

${ }^{10}$ Sobre Mill, cfr. la excelente Tesis Doctoral de J. García Añón, La teoría de la justicia y los derechos morales en J. S. Mill (J. de Lucas director), Valencia, 1994.

${ }^{11}$ Cfr. Bobbio, N., El tiempo de los Derechos, Trad. de Rafael de Asís Roig, Madrid, Sistema, págs. 108 y ss. Sobre la distinción de los distintos tipos de individualismo (metodológico, ontológico y ético) cfr. Laporta, F. J., Sobre la teoría de la democracia y el concepto de representación política: algunas propuestas para debate, en DOXA, 6/89, págs. 121-141. 
del discurso moral ${ }^{12}$. Por ello frente al individualismo liberal que extralimita la autonomía como facultad de autogobierno e imposibilita la convivencia por su carácter absoluto, cabe un individualismo democrático que, manteniendo la autonomía limitada de los individuos fundamenta la existencia política mediante el consenso y el contrato. Como al respecto apunta Bobbio, «ninguna concepción individualista de la sociedad prescinde del hecho de que el hombre es un ser social ni considera al individuo aislado ${ }^{13}$. En la misma línea se manifiesta E. Díaz cuando afirma que la libertad individual (positiva y negativa) es la base de la democracia que radica en la autonomía de la persona, la autoconciencia y la toma de decisiones por uno mismo ${ }^{14}$.

En pocas palabras y siguiendo a Bobbio, «el individuo es la base filosófica de la democracia: una cabeza, un voto» ${ }^{15}$. En este punto radica para Bobbio, la justificación de la prioridad que los regímenes democráticos confieren a los derechos sobre los deberes: «concepción individualista significa que primero está el individuo, se entiende el individuo singular, que tiene valor por sí mismo y después está el Estado y no viceversa ${ }^{16}$. No se trata pues de insistir en la conjunción de liberalismo y democracia que no es tan clara como parece puesto que por ejemplo según se ponga el acento en la libertad negativa o positiva puede existir un régimen coherentemente liberal y limitadamente democrático (como sucede en Locke y en Mill), y a la vez plenamente democrático y nada liberal (un régimen en el que la mayoría no reconozca las minorías, como sucede en la lectura de Rousseau por Talmon), e incluso se puede ser coherentemente liberal y nada democrático como lo fue Kant, sino de situar el tema en el ejercicio de las propias libertades que constituyen la autonomía para afirmar en ese punto sí, que el régimen democrático se asienta sobre el principio individualista y liberal y se opone algunas concepciones perfeccionistas y/o paternalistas, que como puede suceder con las tesis del coto vedado y de la inalienabilidad de los derechos humanos, anteponen una concepción del bien, siquiera con la justificación de salvar el riesgo apuntado por Garzón Valdés de las instituciones

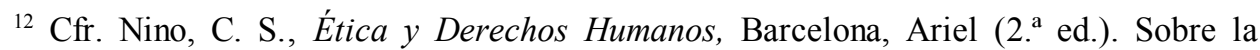
concepción del autor, vide Rosenkrantz, C., La democracia: una crítica a su justificación epistémica, en DOXA, 10/91, págs. 261-277, y Ródenas, A., Sobre la justificación de la democracia en la obra de Carlos. S. Nino, en DOXA, 10/91, cit, págs. 279-293.

${ }^{13}$ Cfr. Bobbio, N., El individualismo y el organicismo, en Liberalismo y Democracia, México, FCE, 1992, págs. 49 -53.

${ }^{14}$ Cfr. Díaz, E., La justificación de la democracia, cit., pág. 5.

${ }^{15}$ Cfr. Bobbio, N., El tiempo de los Derechos, op. cit., pág. 108.

${ }^{16}$ Cfr. Bobbio, N., El tiempo de los Derechos, op. cit., pág. 107. 
suicidas que por ello, sustraen a la decisión de la mayoría lo que se refiere a estos extremos ${ }^{17}$.

\section{II.3. El relativismo}

La tesis del coto vedado trata de limitar el relativismo inherente a todo régimen democrático, sustrayendo de la discusión y decisión por mayorías algunos elementos sin los cuales el régimen perdería su significación. En efecto, si es verdad, como advierte Bobbio que pluralismo y democracia pueden no coincidir puesto que hay regímenes pluralistas que no son democráticos (el régimen feudal y en general el orden político medieval), y regímenes democráticos no pluralistas (las democracias antiguas) ${ }^{18}$, lo bien cierto es que la democracia conlleva el relativismo. Así lo señala, siguiendo a Kelsen, Garzón Valdés cuando indica que la concepción kelseniana presupone estos tres elementos: primero, el relativismo axiológico versus el objetivismo; segundo, la negociación y el compromiso que implican la tolerancia y constituyen el núcleo de la actividad parlamentaria, y, finalmente la nota de la homogeneidad social ${ }^{19}$.

Cierto es, y así lo advierte, Ruiz Manero que en Kelsen «el relativismo ético es condición necesaria y suficiente del democratismo político» lo que no excluye la existencia de contraejemplos como los de Mill, que reúne objetivismo y democratismo para el que el relativismo no es condición necesaria de la democracia, y Hobbes para quien el relativismo no es condición suficiente de la democracia. Ello no obstante, la conclusión para Ruiz Manero es clara «si como Kelsen gusta de repetir democracia es discusión, emplear la discusión para determinar las reglas del ordenamiento social no tiene sentido, desde luego, si se parte de la existencia de verdades morales absolutas, inmunes al examen crítico-racional, que nos sirvan de patrón absolutamente válido para la conformación de tales reglas $»^{20}$. De ahí que frente a la concepción tradicional que considera absolutos a los derechos humanos e imposibilita el diálogo y la discusión, la doctrina se refiera al carácter resistente de los derechos fundamentales

\footnotetext{
${ }^{17}$ Cfr. Garzón Valdés, E., Instituciones suicidas, en Isegoría, n. ${ }^{\circ}$ 9/94, págs. 65-128.

${ }^{18}$ Cfr. Bobbio, N., Il futuro de la Democrazia, Torino, Einaudi, 1984, págs. 48. Hay trad. castellana, Barcelona, Plaza y Janés, 1985.

${ }^{19}$ Cfr. Garzón Valdés, E., Representación y Democracia, en DOXA 6/89 págs. 143-163.

${ }^{20}$ Cfr. Kelsen, H., Escritos sobre la democracia y el socialismo. Selección y presentación de J. Ruiz Manero, Madrid, Debate, 1988, págs. 14 y ss.
} 
que no afecta el relativismo, la tolerancia y la libre discusión, que definen el sistema democrático ${ }^{21}$.

\section{Los límites a las mayorías}

III.1. Derechos humanos y principio de decisión por mayorías

La existencia de instancias de legitimidad externas al proceso democrático plantea el problema de la existencia de límites al criterio de las mayorías que en nuestra comunidad cobra especial relevancia en torno a los Derechos humanos que para unos definen el coto vedado y para otros constituyen supuestos de inalienabilidad. La historia de Doxa refleja esta cuestión en los números dedicados a los problemas derivados del concepto y fundamento de los Derechos Humanos (n. $\left.{ }^{\circ} 4\right)$, del Paternalismo (n. $\left.{ }^{\circ} 5\right)$, de los conceptos de Representación y Democracia (n. $\left.{ }^{\circ} 6\right)$, de la Tolerancia y el Comunitarismo (n. $\left.{ }^{\circ} 12\right)$.

No es la decisión por mayorías sino el sufragio universal a través del principio mayoritario quien define el régimen democrático. Ahora bien el principio de mayorías muestra siguiendo a Bobbio y a Peces-Barba la deslegitimación de los argumentos de autoridad y expresa el relativismo filosófico y el pluralismo ideológico. Es cierto que hay límites que la decisión por mayorías no debe traspasar. Las cuestiones científicas, como la propia racionalidad y razonabilidad de la decisión, y en última instancia la renuncia a la libertad en el ejercicio de la libertad (Mill, Rousseau) constituyen algunos ${ }^{22}$.

El punto de partida podría ser, siguiendo a E. Díaz el siguiente: la justificación ética del Derecho y del Estado se concreta hoy en la defensa y realización de una serie de derechos humanos básicos derivados de la libertad, pero también de la igualdad y de la solidaridad, considerados totalmente imprescindibles y que no deben sacrificarse a otras instancias transpersonalistas ${ }^{23}$. Si esto es cierto, ¿cabría sostener que una vulneración de esos derechos básicos, aún a través de la legitimidad democrática, constituye una perversión del régimen democrático que anula la legitimidad y por consiguiente destruye la justicia y la justificación de la decisión? Este es el núcleo de lo que hoy en día definen constitucionalismo y el garantismo como técnicas al servicio de la libertad que se manifiesta en la tradición

${ }^{21}$ Cfr. Prieto Sanchís, L., Estudios sobre derechos fundamentales, cit., págs. 99.

${ }^{22}$ Cfr. Bobbio, N., La regola di maggioranza: limiti e aporie, en Bobbio. Offe, Lombardini, Democrazia, maggioranza e minoranze, Bologna, II Mulino, 1981, págs. 33-72.

${ }^{23}$ Cfr. Díaz, E., Ética contra Política cit., pág. 24. 
del gobierno de las leyes frente al gobierno de «reyes» ${ }^{24}$. La consecuencia es clara; si ello es así (y piénsese en lo que sucede en la actualidad en nuestra sociedad respecto de la eutanasia, o en un ámbito intercultural y transnacional con la cuestión en torno del aborto que se ha suscitado en la reciente Conferencia de El Cairo sobre Población y Desarrollo), ¿no se estaría tutelando mediante un catálogo de verdades inatacables, la autonomía individual, el pluralismo y el relativismo que constituyen el fundamento de la decisión democrática? Desde su origen el garantismo intenta limitar la potestad de las mayoría, manteniendo el principio de la soberanía, pero negando frente a Rousseau que ello implique capacidad de disponer soberanamente de la existencia de los individuos y de sus derechos y libertades fundamentales. En este sentido el constitucionalismo, entendiendo por tal siguiendo a MacCormick, «la doctrina legal según la cual el poder político sólo debe ser ejercido bajo las disposiciones constitucionales y sometido a los límites constitucionales» representa la antítesis de la democracia; para el autor escocés, la democracia entendida como gobierno de la mayoría pura, sin trabas, es una doctrina anticonstitucional, por lo que concluye afirmando que el constitucionalismo es un requisito previo a la democracia ${ }^{25}$. En la misma línea, si bien con alguna importante matización puesto que el constitucionalismo no es como para MacCormick un elemento antitético de la democracia cuanto su complemento necesario y sustancial se pronuncia Ferrajoli cuando dice que los derechos fundamentales se configuran como otros tantos vínculos sustanciales impuestos a la democracia política que aparece limitada y vinculada por dichos derechos que son indisponibles e inalienables tanto a la decisión política como al mercado como a su propio titular punto este último en que discrepo del profesor italiano, puesto que una cosa es la indisponibilidad frente al mercado y otra muy distinta la indisponibilidad frente al propio sujeto, contradictoria con la titularidad ${ }^{26}$. Si aceptamos esta tesis, tendremos que repensar la tesis sobre la Norma Fundamental de nuestra Constitución, en donde el art. 1.2, de la Constitución, sería reemplazado por el art. 10 en que define el coto vedado en torno a la persona y los derechos fundamentales interpretados conforme con la Declaración Universal de los Derechos Humanos ${ }^{27}$.

${ }^{24}$ Cfr. Bobbio, N., Il futuro de la Democrazia, Torino, Einaudi, 1984, págs. 148-169. Hay trad. castellana, Barcelona, Plaza y Janés, 1985.

${ }^{25}$ Cfr. MacCormick, N., Constitucionalismo y Democracia, en $A D H s$, n. ${ }^{\circ}$ 5/88-89, págs. 367-380.

${ }^{26}$ Cfr. Ferrajoli, L., El Derecho como sistema de garantías, trad. de Perfecto A. Ibáñez en $J P D$, n. $^{\circ}$ 23/92, págs. 61-69.

${ }^{27}$ Cfr. Rodríguez Paniagua, J. M. ${ }^{\text {a }}$, El artículo 10.1 de la Constitución Española y la fundamentación ética de los Derechos Humanos, en Lecciones de 
En sentido fuerte las tesis del coto vedado como la de la inalienabilidad de los Derechos humanos pese a sus indudables diferencias, constituyen límites tan severos que pueden llegar a anular el principio de autonomía individual que sustenta la legitimidad última de los valores principios y normas que integran el ordenamiento jurídico. Si como se ha señalado, el gran logro del régimen democrático consiste en la superación de la escisión entre autonomía de la moral y heteronomía del Derecho que justifica la obediencia al mismo, ya que como mandato autónomo que es, el Derecho no fuerza sino que obliga y cabe por consiguiente tanto la obediencia como la desobediencia al Derecho ${ }^{28}$ por razones morales y a fortiori, jurídicas, la existencia de esos límites corre el riesgo de empañar este avance decisivo. Estoy de acuerdo por ello con Peces-Barba cuando señala que «la teoría democrática supone el más importante esfuerzo hasta ahora realizado para conseguir una racionalización de la obligación política y de la obediencia al Derecho en tanto en cuanto convierte al ciudadano en partícipe de la voluntad política con lo que coinciden el poder con el titular de la obligación política y con el destinatario de las normas y en tanto en cuanto institucionaliza y encauza la resistencia por medio de los derechos fundamentales en sus diversas perspectivas» ${ }^{29}$.

\section{III.2. El coto vedado}

Como señala J. de Lucas, para esta concepción los Derechos Humanos integran un catálogo de bienes primarios que quedan al margen del criterio de las mayorías ${ }^{30}$. Para Garzón Valdés «los derechos incluidos en el coto vedado, son aquellos vinculados con la

Derecho natural como introducción al Derecho, Madrid, Univ. Compl. 1988 (3. a ed.), págs. 205 a 209.

${ }^{28}$ Cfr. González Vicén, F., La Obediencia al Derecho, en Estudios de Filosofía del Derecho, La Laguna, 1979, págs. 365-398. De Lucas, F. J., ¿Por qué obedecer las leyes de la mayoría? en A.A. V.V., Etica y política en la sociedad democrática, Madrid, Espasa-Calpe, 1981, págs. 167-257. Atienza, M., La filosofía del Derecho de Felipe González Vicén en R. F. D. U.C., n. ${ }^{\circ} 62 / 81$ págs. 84 y ss. Díaz, E., De la maldad estatal y la soberanía popular, Madrid, Debate, 1984, págs. 76-94. Maguera, J., La Obediencia al Derecho, Madrid, Civitas, 1987, y Estudios de Ética Jurídica, Debate Madrid, 1990, págs. 79-97. Guisan, E., Razones morales para obedecer al Derecho en A. C. F. S., n. ${ }^{\circ} 28 / 88$, págs. $131-153$.

${ }^{29}$ Cfr. Peces-Barba Martínez, G., La concepción democrática de la obediencia, en El País, 29-III-80, pág. 12, ahora en Derecho y Derechos fundamentales, Madrid, CEC, 1993, págs. 373-384.

${ }^{30} \mathrm{Cfr}$. De Lucas, J., El desafio de las fronteras. Derechos humanos y xenofobia frente a una sociedad plural, Madrid, Temas de Hoy, 1994, págs. 74-91. 
satisfacción de los bienes básicos, es decir que son condición necesaria para la satisfacción de cualquier plan de vida $\iota^{31}$. La existencia del coto vedado plantea inmediatamente el problema del paternalismo, de siempre difícil justificación ${ }^{32}$ y se extiende a los que se derivan de la representación política puesto que como observa, J. de Lucas está claro que existiría un grupo de cuestiones que afectan a la institución de la representación y quedan fuera del alcance de disposición de los representantes» ${ }^{33}$. Todo ello implica una limitación considerable a los principios de relativismo, tolerancia y autonomía sobre los que se asienta el régimen democrático y se convierte en una seria amenaza para su legitimidad. Porque de lo que se trata es de descubrir, conocer, proteger, tutelar ese catálogo de verdades autoevidentes, que supuestas (en el supuesto de incorporación a un ordenamiento jurídico positivo del catálogo de derechos naturales) o puestas (en el caso de «construcción» de dicho catálogo a través de la decisión por mayorías de algo que ya no se podrá alterar) constituyen e integran el coto vedado.

Amenaza asimismo la existencia de la minoría que es también condición de existencia de la democracia: si lo que constituye la democracia es el principio de mayoría y este se asienta como muy bien se ha señalado sobre el respeto de la minoría, no parece que uno y otro, por definición coexistan frente al coto vedado, en donde no hay discusión ni decisión ni autonomía, sino acatamiento. Paradójicamente el coto vedado, en sentido fuerte atenta contra lo que constituye la democracia que Kelsen resume en tres puntos: la idea del relativismo versus el objetivismo, la existencia de la negociación y el compromiso como medios de soluciones los conflictos sociales y la homogeneidad social como elemento sobre el que se asienta la democracia. A este respecto no queda sino asumir la impecable exposición de J. de Lucas cuando entendiendo la homogeneidad social en sentido normativo como «la existencia de un consenso en torno a un minimum ético que decían los clásicos, a un código de valores que actúa como mínimo común denominador que es lo que hoy parece representar la Constitución $»^{34}$,

${ }^{31}$ Cfr. Garzón Valdés, E., Algo más acerca del coto vedado, DOXA, 6/89, págs. 209 y ss. Sobre los bienes básicos, cfr. Añón Roig, M. ${ }^{\mathrm{a}}$ J., Necesidades básicas y Derechos. Un ensayo de fundamentación, Madrid, CEC, 1994, págs. 283 y ss.

${ }^{32}$ Cfr. DOXA, 5/89, con artículos de Garzón Valdés, Dieterlen, Camps, Atienza y De Lucas. Vide también Atienza, M., Paternalismo y Consenso, en J. Maguera, y otros, El fundamento de los Derechos Humanos, G. Peces-Barba ed., Madrid, Debate, 1989, págs. 187-199.

${ }^{33} \mathrm{Cfr}$. De Lucas, J., Sobre la justificación de la democracia representativa, en DOXA 6/89, cit., págs. 187-199.

${ }^{34}$ Cfr. De Lucas, J., El desafío de las fronteras. Derechos humanos y xenofobia 
advierte que tanto en la versión habermasiana del patriotismo de la constitución, o en la concepción de Garzón Valdés sobre el coto vedado se genera una uniformidad y un consenso moral sustraído a la discusión pública que exige aceptación y crea resistencia y rechazo frente a los disidentes y a los diferentes.

Si llevamos esta tesis al extremo, podríamos perfectamente admitir la existencia de un Derecho justo que no emanase de un poder legítimo en la concepción tradicional del déficit de legitimidad (quod titulum) o de un poder legítimo en su origen que al limitar la libertad de decisión de aquellos que lo han constituido ha perdido su legitimidad (quod exercitium), siendo este un riesgo claro de pérdida o cuando menos de déficit de legitimidad que afecta a nuestras democracias en donde no sólo los derechos fundamentales que integran el coto vedado quedan inmunes a la discusión sino, y lo que es más grave, a través de la aparición de otros cotos vedados (lo concerniente a la Defensa Nacional y los Secretos de Estado), imponer por medio del secreto y la negación del principio de publicidad ${ }^{35}$, la primacía de la razón de Estado.

\section{III.3. La Inalienabilidad}

Quienes afirman la inalienabilidad se sitúan en la línea del comunitarismo que postula la existencia de instancias superiores al individuo sobre las que no puede decidir, defendiendo esos derechos como apunta Ballesteros, «frente a la voluntad individual del sujeto de los mismos», y apostando en consecuencia por «la inalienabilidad de los Derechos humanos que integran los bienes clásicos $»^{36}$. En esta línea Martínez Pujalte defiende el carácter inalienable de los Derechos Humanos, entendiendo por derechos inalienables, «aquellos sobre los cuales el titular no puede llevar a cabo actos de disposición» ${ }^{37}$.

Creo que en esta tesis hay una confusión entre el plano moral y el jurídico y una consiguiente extrapolación de las consecuencias. Nada que objetar a cuanto se argumenta respecto a la indisponibilidad de la dignidad como principio moral en Kant. Mill defiende otros principios y no creo que esté renunciando a la dignidad de cada cual. En cambio me parece contradictorio como ya he mostrado en págs. 131-148.

${ }^{35}$ Cfr. De Lucas, J., Anotaciones sobre el principio kantiano de publicidad. DIANOIA, 1987, pág. 146.

${ }^{36}$ Cfr. Ballesteros. J., Postmodernidad: decadencia o resistencia, Madrid, Tecnos, 1989,

${ }^{37}$ Cfr. Martínez Pujalte, A. L., Los Derechos Humanos como derechos inalienables. En Derechos Humanos (J. Ballesteros ed.) cit., págs. 86-99. 
otro lugar ${ }^{38}$, afirmar, en el plano jurídico la titularidad y negar su plena disponibilidad, que son conceptos correlativos. Los actos que se realizan en el ejercicio pleno de un derecho y como tal la renuncia son actos libres cuando su titular es el dominus del derecho. En otro caso son actos debidos de cuyo ejercicio se debe responder a un tercero. La renuncia en nuestro ordenamiento es un acto libre, pues sólo aparece limitado en perjuicio de tercero, no de uno mismo, o como apunta Ruiz Miguel en relación con el conflicto suscitado entre el derecho a la libertad y el derecho a la vida de miembros de los GRAPO, tiene una dimensión interpersonal y no intrapersonal, probablemente porque se piense que este es un asunto más moral que jurídico, lo que abona la tesis que aquí sostengo ${ }^{39}$. Por consiguiente, si se mantiene la inalienabilidad habrá de admitirse que la titularidad sobre el derecho no es plena sino limitada y que se ejercerá un acto que es debido y no libre, reemplazando por consiguiente el principio liberal por el paternalista. Una versión «light» de la inalienabilidad sería la tesis que inmuniza los derechos inalienables frente a la voluntad de su titular que en todo caso tendría un poder mediato sobre ellos, y hace posible su inclusión aunque no su exclusión del coto vedado ${ }^{40}$.

\section{Conclusión}

En esta línea mi propuesta iría encaminada a la recuperación de la autonomía individual entendida como facultad de darse leyes a sí mismo que comprende el ejercicio de la libertad, negativa frente al Estado paternalista y las concepciones comunitarias y/o perfeccionistas extremas, como de la libertad positiva democrática y de participación y que constituye la condición sine qua non del régimen democrático que se justifica procedimental y materialmente en tanto en cuanto es manifestación y expresión de dicha libertad en el ejercicio de la autonomía. Ello es compatible con la existencia de medidas paternalistas cuya justificación sería precisamente la de suplir y en todo caso aumentar la libertad de los que están positivamente afectados por ellas, pero creo por el contrario que es difícilmente compatible.

${ }^{38}$ Cfr, Vidal Gil, E. J., Los Derechos Humanos como derechos subjetivos, en Derechos Humanos (J. Ballesteros, ed.), cit., págs. 22-41.

${ }^{39}$ Cfr. Ruiz Miguel. A., Autonomía individual y derecho a la propia vida (un análisis filosófico jurídico). Revista del CEC, n. ${ }^{\circ}$ 14/93, págs. 135-165. Vide además, Atienza, M., La argumentación jurídica en un caso difícil: la huelga de hambre de los presos del GRAPO, en JPD, n. ${ }^{\circ}$ 9/90, págs. 31-41.

${ }^{40}$ Cfr. Laporta, F., Sobre el concepto de Derechos Humanos, DOXA, 4/87, págs. 23-45. 
La existencia del coto vedado como la concepción de la inalienabilidad de los derechos sean fundamentales morales o naturales, capaces de obstaculizar o impedir esas libres decisiones populares convertibles en ley como apunta E. Díaz ${ }^{41}$, son límites que si no anulan, sí aminoran considerablemente el ejercicio de la autonomía. En este sentido es decisiva, aunque insuficiente la afirmación de E. Fernández, «si los derechos morales son previos al contrato, esto quiere decir que son anteriores a cualquier legislación o convención, incluida la que aquí se considera la más legítima que es la democrática. Si los derechos morales son previos al sistema democrático, ello quiere decir también que los derechos morales tienen prioridad axiológica sobre la democracia. Aunque un sistema democrático se caracteriza generalmente, y entre otros rasgos, por el respeto a los derechos morales de los individuos, lo anterior quiere decir, como última conclusión, que pierde justificación por injusta, cualquier decisión o disposición tomada democráticamente que atente contra los derechos morales de las personas. Los derechos morales funcionan, así, como límites a priori del contrato y como control a posteriori de la democracia. La última conclusión no expresa desconfianza ante la democracia, sino más bien tomarla en serio, como una forma de organización política de la convivencia de los ciudadanos, que materializa los contenidos morales de autonomía libertad e igualdad $»^{42}$. Insuficiente porque no estará de más señalar la paradoja que supone para la concepción liberal fundamentar los derechos en la autonomía y a la vez sustraerlos del consenso, mediante el recurso a su carácter absoluto e inmutable, o a través de la inalienabilidad y el coto vedado. Estamos ante la paradoja de la positivación que siguiendo a Rafael de Asís, en un excelente estudio del tema, «se produce porque los derechos fundamentales son límites al poder, pero a la vez es el propio poder el que los reconoce ${ }^{43}$. Como bien señala Prieto, el fundamento de los derechos no puede ser previo al consenso, sino reposar en el consenso mismo ${ }^{44}$.

Por ello creo que la legitimidad democrática es condición necesaria y suficiente para justificar un determinado régimen. Por supuesto que ello incluye siguiendo a E. Díaz una legitimidad mudable abierta a los cambios y a la reversibilidad incluso del propio régimen que constituye como es sabido la clave de reconocimiento del sistema

${ }^{41}$ Cfr. Díaz, E., Ética contra Política, cit., pág. 56-57.

${ }^{42}$ Cfr. Fernández, E., La Obediencia al Derecho, Madrid, Civitas, 1987, págs. 176 y 177.

${ }^{43}$ Cfr. De Asís Roig, R., Las paradojas de los derechos fundamentales como límites al poder, Madrid, Debate, 1992, pág. 74.

${ }^{44}$ Cfr. Prieto Sanchís, L., Ideología liberal y fundamentación iusnaturalista de los Derechos Humanos. Observaciones críticas, ADHs, 4/87, págs. 291-321. 
democrático. En consecuencia y siguiendo a $\mathrm{Kant}^{45}$ la única limitación que considero legítima y justificada del soberano legal que frente al absoluto está sujeto a la ley, a sí mismo y a los demás, deriva de su propio deber de obediencia a la ley. La renuncia al ejercicio de la libertad sería pues, la única condición que limitaría el ejercicio de la libertad.

${ }^{45}$ Cfr. Bobbio, N., Diritto e Stato nel pensiero di Emanuele Kant, Torino, Giappichelli, 1969 , págs. 255 y ss. 
